\title{
Carbogen Breathing
}

National Cancer Institute

\section{Source}

National Cancer Institute. Carbogen Breathing. NCI Thesaurus. Code C16030.

Increases the oxygenation of tumors thereby enhancing the effect of radiation therapy. 